\title{
The Role of Oxygen in $\alpha_{2}$ Formation in the Titanium Model Alloy Ti-7Al
}

\author{
H. M. Gardner ${ }^{1}$, A. Radecka ${ }^{2}$, D. Rugg ${ }^{2}$, D. E. J. Armstrong ${ }^{1}$, M. P. Moody ${ }^{1}$ and P. A. J. Bagot $^{1}$
}

1. Department of Materials, University of Oxford, Oxford OX1 3PH, United Kingdom.

2. Rolls-Royce plc, Derby, DE24 8BJ, United Kingdom.

Corresponding Author: hazel.gardner@materials.ox.ac.uk

\begin{abstract}
$\underline{\text { Abstract }}$
The mechanical and microstructural response of a model Ti-7wt.\%Al alloy doped with 500 wppm oxygen has been examined in detail as a function of ageing. Three ageing conditions, ice-water quenched, and aged at $550{ }^{\circ} \mathrm{C}$ for 10 or 49 days were examined in detail as a function of ageing. Nanoindentation was used to measure hardness as a function of ageing, while Atom Probe Tomography (APT) also revealed $a_{2}$ precipitation in the aged samples. The partitioning preference of oxygen to the a matrix instead of the $a_{2}$ precipitates has been directly measured.
\end{abstract}

\section{Introduction}

Titanium is widely used in the aerospace industry owing to its high specific fatigue strength and good corrosion resistance. Approximately $35 \%$ of a jet engine is made from titanium [1], with other components being made from nickel, steel, aluminium and composites. Titanium components include fan blades/ discs and compressor blades/ discs, all of which are located towards the front end of a jet engine, ahead of the combustion chamber [2]. Fan blades operate at lower temperatures, up to about $315^{\circ} \mathrm{C}$, and are therefore often made from the common workhorse alloy Ti-6Al-4V whereas compressor discs are made from the alloy IMI 834, designed for improved creep resistance over Ti-6Al-4V, which can operate at temperatures approaching $600^{\circ} \mathrm{C}[2]$.

Even trace amounts of oxygen are known to strengthen, but also embrittle titanium alloys [3]-[5]. Specifically, oxygen has been shown to have a detrimental effect on mechanical properties by encouraging formation of the embrittling $a_{2}$ phase, $\mathrm{Ti}_{3} \mathrm{Al}$. The $\mathrm{a}_{2}$ phase typically forms via chemical ordering of alpha titanium during

thermal ageing at temperatures between $500-700^{\circ} \mathrm{C}$ [6], although the precise mechanism is not well understood. It has been suggested that this chemical ordering causes dislocations to travel in pairs through the ordered regions, as evidenced by a transition from homogeneous to planar slip [7]. This causes strain localisation. Thus it is thought that formation of the ordered $\mathrm{Ti}_{3} \mathrm{Al}$ phase as a result of ageing at intermediate temperatures, such as those experienced during the processing of fan blades, could make the alloy more susceptible to cold dwell fatigue [8].

Previous papers [6], [9] have qualitatively described the effect of oxygen on $a_{2}$ formation but not quantified the amount of oxygen needed to form $a_{2}$, nor defined the mechanism by which oxygen actually encourages $a_{2}$ precipitation. In this work we directly quantify the oxygen concentration in both the $a$ and $a_{2}$ phase to determine the location and quantity of oxygen within the alloy microstructure and relate this to changes in the hardness measured through nanoindentation.

\section{Materials and Methods}

Materials

Ti-7wt.\%Al, a model alloy with composition similar to that of the alpha phase of Ti-6Al-4V, was supplied by TIMET Witton, Birmingham, UK. The material was melted, using an Arc furnace, at Imperial College London and 500 wppm oxygen was introduced into the melt via addition of TiO ${ }_{2}$ powder. The material was rolled at $900^{\circ} \mathrm{C}$ and then recrystallised at $980^{\circ} \mathrm{C}$ for 1 hour before being quenched in ice water.

Pieces of the ice water quenched material were treated for 10 days at $550^{\circ} \mathrm{C}$ and 49 days at $550^{\circ} \mathrm{C}$. Samples were encapsulated under argon before that treatment. Nanoindentation

Nanoindentation was performed on samples that had been ground using 600-4000 grit SiC paper, polished with $3 \mu \mathrm{m}$ to $1 \mu \mathrm{m}$ diamond suspension and then polished with colloidal silica solution neutralised with hydrogen peroxide.

A NanolndenterXP (MTS) was used to create arrays of $2 \mu \mathrm{m}$ deep indents using a diamond Berkovich indenter. The contact stiffness was continually measured using the continuous stiffness measurement (CSM) technique ( $2 \mathrm{~nm}$ amplitude, $50 \mathrm{~Hz}$ oscillation) and was used to assess the quality of the indentation data. All indents used here have a near linear depth vs. load/stiffness, which indicates suitable sample mounting and good contact between tip and surface. Hardness values reported are derived from the CSM data and averaged between depths of 1250-1750 nm.

Atom Probe Tomography (APT)

Samples for atom probe tomography (APT) were prepared on a Zeiss NVision 40 FIB-SEM (focussed ion beam scanning electron microscope) using the standard liftout method [10]. APT samples were then analysed with a CAMECA LEAP 5000 HR system, using a laser energy of 40 pJ at a stage temperature of $50 \mathrm{~K}$ with a pulse frequency of $200 \mathrm{kHz}$. Additional APT samples (not shown) were also analysed in voltage mode (20\% pulse fraction) to confirm any laser artefacts were not affecting composition measurements. APT data analysis was performed using the commercially available Integrated Visualisation and Analysis Software (IVAS) software package (Cameca) and the open access 3Depict software (threedepict.sourceforge.net, version 0.0.21).

Atom probe data is collected by using a voltage or laser pulse to field ion evaporate single atoms from a sharp $(<100 \mathrm{~nm}$ diameter) needle of the material of interest. Evaporated ions are accelerated by the applied electric field towards a detector. Since the time of flight, position of impact on the detector and order in which each ion is detected are measured, a 3D reconstruction of the evaporated needle can be created. The reconstruction consists of a 3D point cloud in which each point represents an ion for which the chemical identity and spatial location is known.

Precipitate identification

The Pearson coefficient, $\mu$, was chosen as a metric to describe deviation from a random solid solution within this point cloud data, since deviation from a random solution may be an indicator of precipitation [11]. The Pearson coefficient derives from chi-squared statistics, and is used to describe the departure from randomness of an experimental distribution from the theoretical, binomial distribution. It should be noted that $\mu$ can be used to compare changes in degrees of clustering/precipitation across atom probe reconstructions of different sizes. However, quantitative comparisons of the degree of clustering are often not possible [12].

Once deviation from random had been established, precipitates were identified and extracted using the isoconcentration surface method. Proximity histograms (proxigrams [12]) were used to select an appropriate isoconcentration setting by adjusting the value until the position of the interface coincided with the point of inflection of the aluminium concentration profile on the proxigram. Ions contained within the isoconcentration surface were then extracted as precipitates. The

(C) The Authors, published by EDP Sciences. This is an open access article distributed under the terms of the Creative Commons Attribution License 4.0 (http://creativecommons.org/licenses/by/4.0/). 
concentration of the extracted precipitates was calculated using a MATLAB mass spectrum peak deconvolution tool (AtomProbeLab v0.1.4, (2019), http://atomprobelab.sourceforge.net/).

\section{$\underline{\text { Results }}$}

Hardness tests were performed across the Ti-7Al +500 wppm O samples in the ice water quenched, 10 day aged and 49 day aged states. Figure 1 shows that there is reasonable agreement between the predicted hardness for unaged Ti-64 +500 wppm $\mathrm{O}$ calculated using the model from [13], and experimental measurements. There is also no statistically significant hardness increase with ageing time.

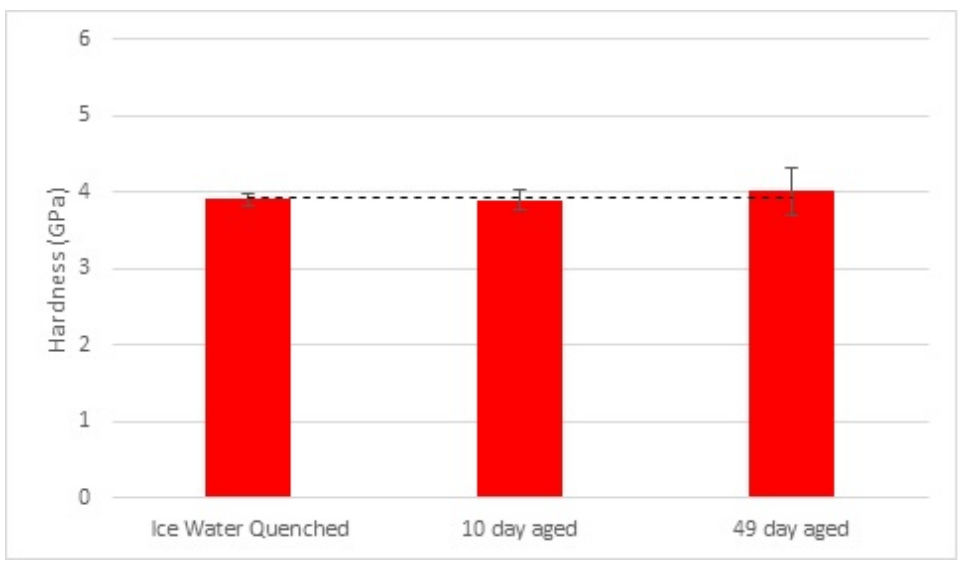

Figure 1: Hardness of the Ti-7 $\mathrm{Al}+\mathbf{5 0 0} \mathrm{wppm} \mathbf{O}$ material as a function of heat treatment. The dotted line shows the predicted hardness value for Ti-64 containing 500 wppm 0 , calculated using the model from [13]. Error bars represent the variation in hardness with crystal orientation.

(a)

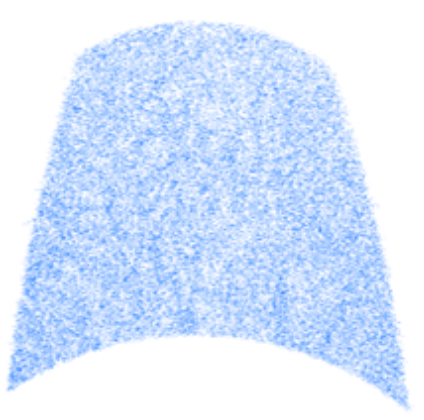

(b)

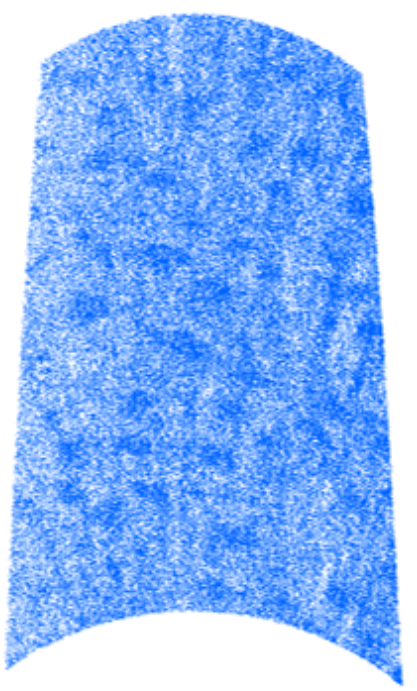

(c)

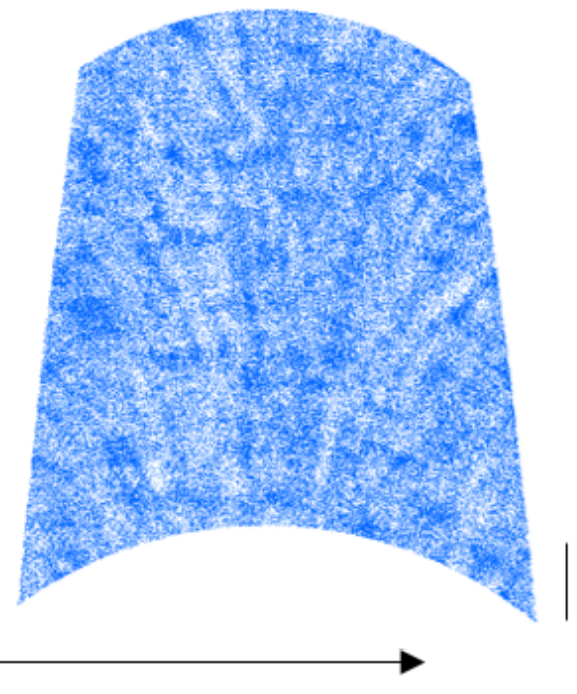

Al

$20 \mathrm{~nm}$

\section{Increasing ageing time}

Figure 2: $4 \mathrm{~nm}$ slices through the atom maps for the Ti-7Al+ $500 \mathrm{wppm} O$ samples after ice water quench (a), ageing for 10 days at $550^{\circ} \mathrm{C}(\mathrm{b})$ and ageing for 49 days at $550^{\circ} \mathrm{C}(\mathrm{c})$. 


\section{$1=$ complete association} $\uparrow$

\section{$0=$ random distribution}

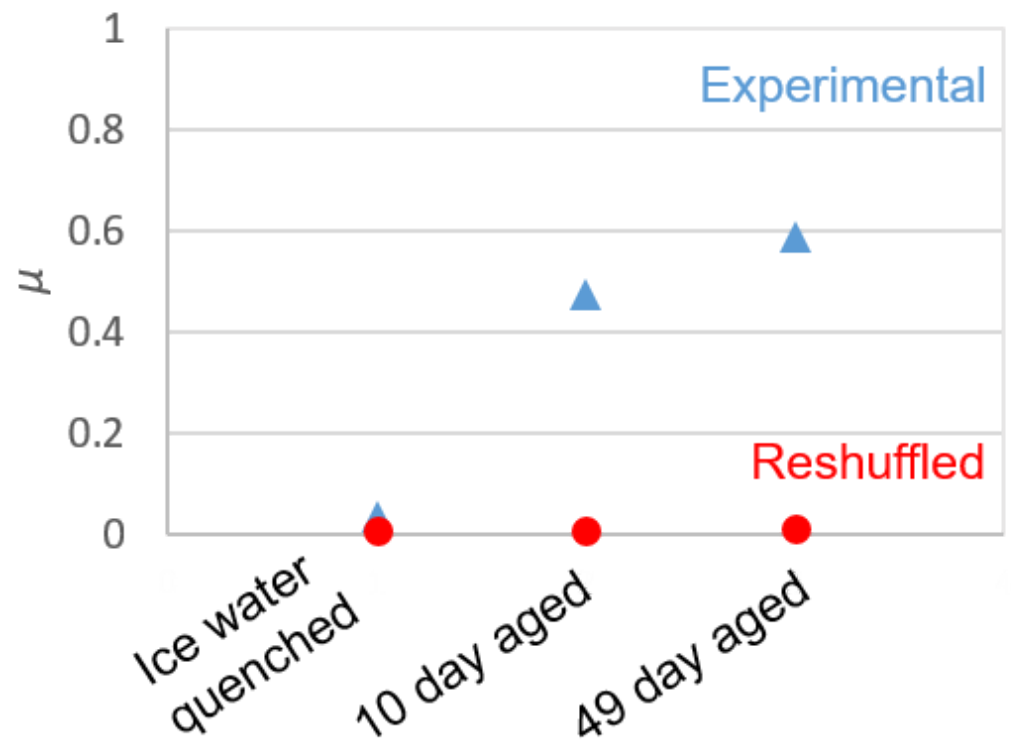

Figure 3: Comparison of the Pearson coefficient $(\mu)$ as a function of ageing time. The degree of non-randomness increases with ageing time.

(a)
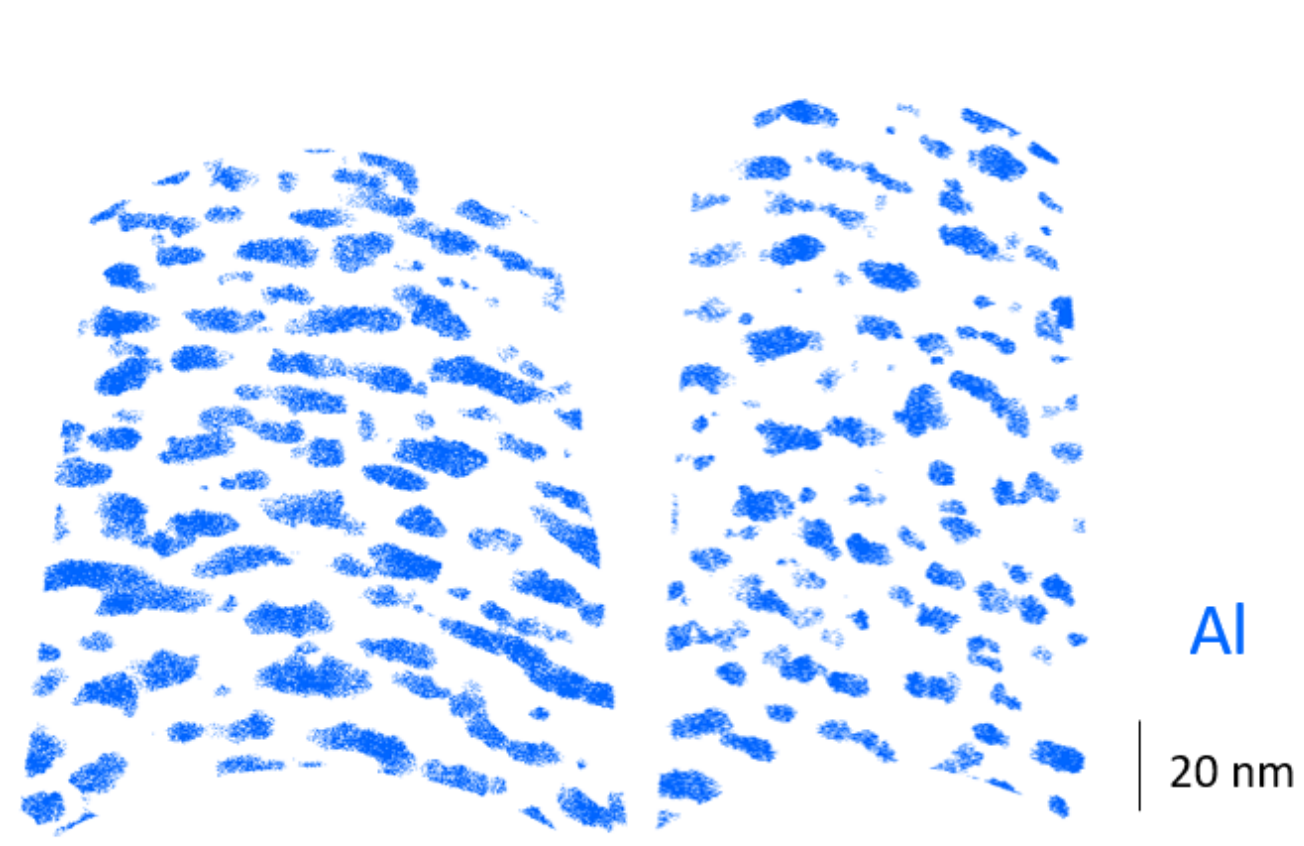

(b)

Figure 4: Precipitates extracted from the Ti-7Al +500 wppm $\mathrm{O}$ sample aged for (a) 10 days at $550^{\circ} \mathrm{C}$ and (b) 49 days at $550^{\circ} \mathrm{C}$. For clarity, a $10 \mathrm{~nm}$ slice is displayed and only aluminium ions are shown.

To investigate if any microstructural changes are taking place during ageing, APT samples of each of the three Ti-7Al+500 wppm $\mathrm{O}$ samples were analysed, the atom maps for which are shown in figure 2. From these, it can be seen that there is clear clustering of aluminium atoms in figure 2 (c). However, it is hard to determine by eye if clustering is occurring in the other samples. Calculation of the Pearson coefficient for the three datasets shows an increase in non-randomness with ageing time; the Pearson value increases from 0.034 to 0.47 to 0.59 from the ice water quenched to 10 day aged to 49 day aged samples, as is shown in figure 3 . For each sample, the Pearson coefficient was also calculated for the reshuffled dataset. The reshuffled dataset contains the same data points in the same spatial locations as the original dataset, except that the mass-to-charge labels of the points have been randomly reshuffled. This means that when the calculation is repeated on this reshuffled data, any non-randomness detected is due to density artefacts in the atom probe data, and not true chemical clustering. The reshuffled dataset can thus be viewed as a control dataset. Ideally, the $\mu$ value of the reshuffled dataset should be close to zero, indicative of a random solid solution, which it is in all 3 cases.

Isoconcentration surfaces were used to extract precipitates, using $1 \mathrm{~nm}$ voxels with a delocalisation value of $3 \mathrm{~nm}$. The isoconcentration analysis was performed on both the original ('experimental') dataset and the reshuffled dataset. In both of the aged samples, the number of precipitates found in the reshuffled dataset was negligible. The ice water quenched sample was not found to contain precipitates. The precipitate ions extracted from the 10 day aged and 49 day aged samples can be seen in figure 4. $\alpha_{2}$ volume fractions were calculated using the Lever rule (eq. 1).

$$
\mathrm{C}_{\mathrm{n}}=\mathrm{C} \alpha_{2} \mathrm{~V} \alpha_{2}+\mathrm{C} \alpha\left(1-\mathrm{V} \alpha_{2}\right)
$$


where $C_{n}=$ overall composition of dataset; $V \alpha_{2}=\alpha_{2}$ volume fraction; $C \alpha_{2}=\alpha_{2}$ composition; $C \alpha=$ matrix composition. This assumes a two phase system, such that $\mathrm{V} \alpha=1-\mathrm{V} \alpha_{2}$. Rearranging eq. 1 and plotting $\mathrm{C}_{\mathrm{n}}-\mathrm{C} \alpha$ against $\mathrm{C} \alpha_{2}-\mathrm{C} \alpha$ gives a straight line with gradient equal to $\alpha_{2}$ volume fraction. It can be seen from figure 5 that the gradient of the Lever rule plot increases from 0.087 to 0.13 from the 10 day aged to the 49 day aged sample, showing that the volume fraction of $\alpha_{2}$ increases with ageing time.
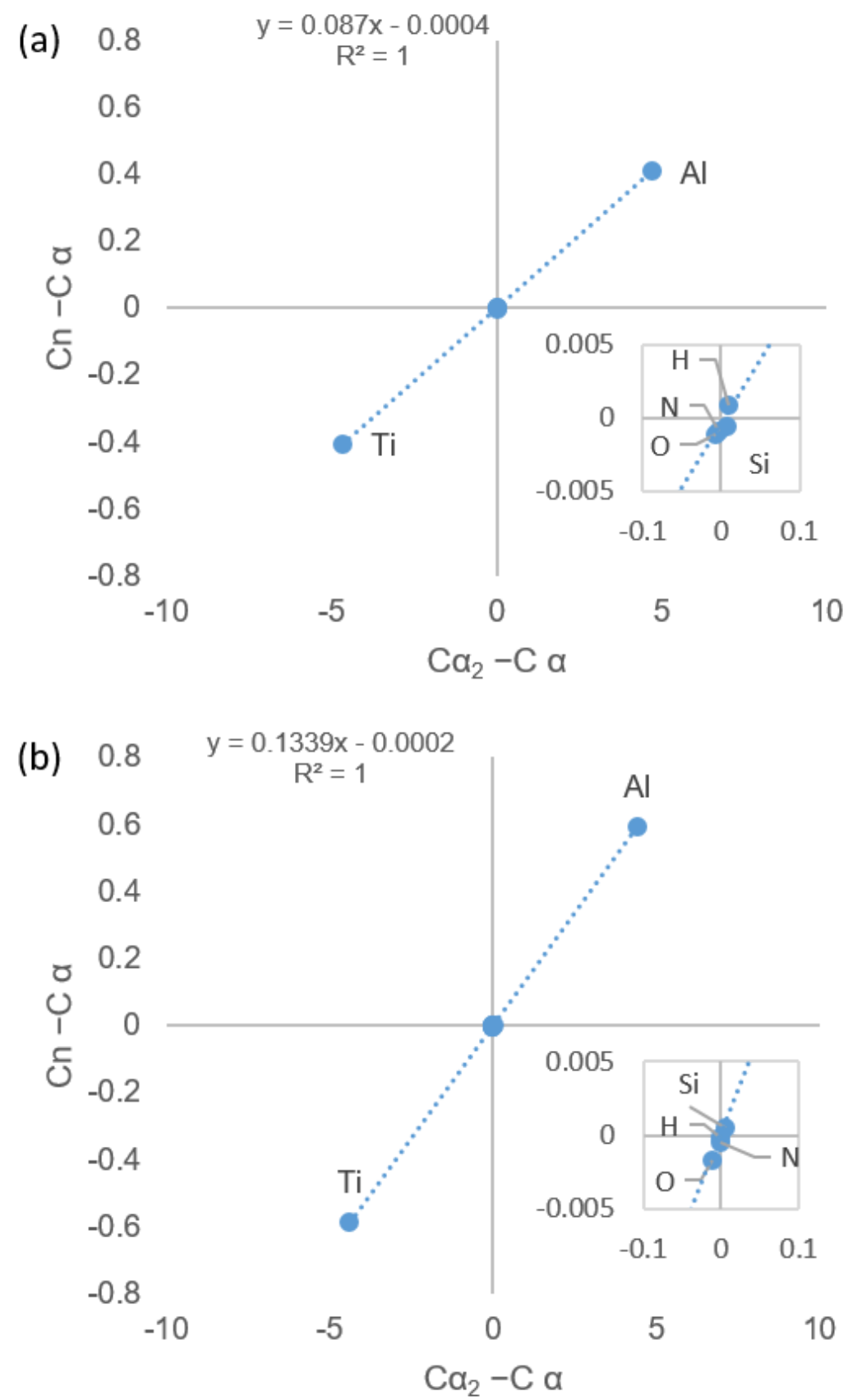

Figure 5: Lever rule plots showing the volume fraction of precipitates (given by the plot gradient) in the (a) 10 day aged and (b) 49 day aged samples. 

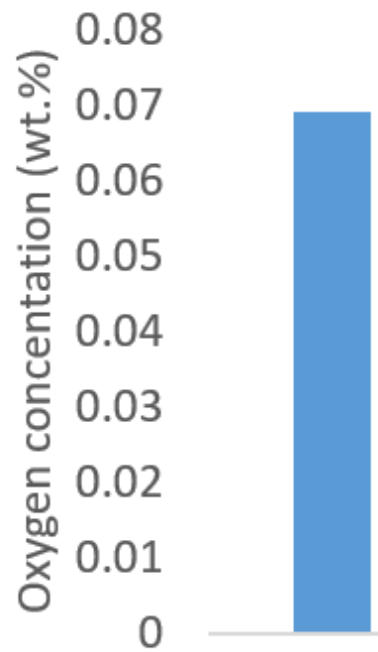

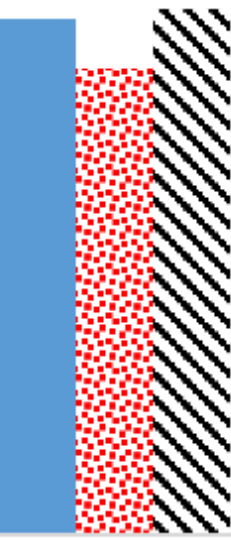

10 day

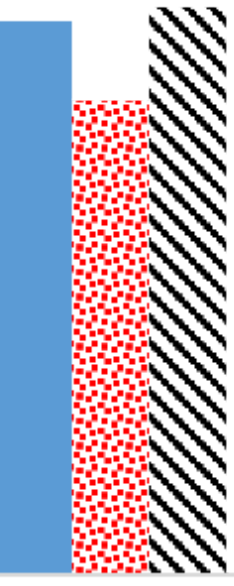

49 day

Bulk Precipitate $\mathbf{s}$ Matrix

Figure 6: APT-measured oxygen concentration of the bulk, precipitates and matrix in each of the IWQ, 10 day aged and 49 day aged samples.

Figure 6 shows the APT-measured oxygen concentration in the bulk (whole APT needle), precipitates and matrix for each of the IWQ, 10 day aged and 49 days samples. The bulk oxygen concentration is consistent between the three samples and for both of the aged samples, the oxygen concentration is higher in the matrix than the precipitates. The precipitate compositions for each of the aged samples are displayed in Table 1 , and oxygen partition coefficients are displayed in Table 2.

Table 1: APT-measured composition of precipitates in the 10 day aged and 49 day aged samples of Ti-7Al $+500 \mathrm{wppm} 0$.

\begin{tabular}{|l|l|l|l|l|}
\hline \multirow{2}{*}{} & \multicolumn{5}{|c|}{ Composition (wt. \%) } \\
\cline { 2 - 5 } & $\mathrm{Ti}$ & Al & $\mathbf{0}$ & $\mathrm{N}$ \\
\hline 10 day aged & 89.1 & 10.7 & 0.062 & 0.009 \\
\hline 49 day aged & 89.6 & 10.3 & 0.065 & 0.018 \\
\hline
\end{tabular}

Table 2: Oxygen partition coefficient as a function of ageing time.

\begin{tabular}{|c|c|c|c|}
\hline $\begin{array}{c}\text { Oxygen partition } \\
\text { coefficient }\end{array}$ & Ageing time (days) & $\begin{array}{c}\text { Nominal oxygen } \\
\text { content (wt.\%) }\end{array}$ & $\begin{array}{c}\text { Ageing temperature } \\
\left({ }^{\circ} \mathrm{C}\right)\end{array}$ \\
\hline 1.13 & 10 & 0.05 & 550 \\
\hline 1.20 & 49 & 0.05 & 550 \\
\hline
\end{tabular}

\section{$\underline{\text { Discussion }}$}

The hardness measurements reported in figure 1 show that as ageing time is increased, there is no statistically significant change in hardness. However, the increase in Pearson coefficient with increasing ageing time seen in figure 3 , shows that the alloy is becoming increasingly non-random as ageing progresses. The high spatial resolution of APT reveals that this increase in non-randomness is clearly due to precipitation, which can be seen in the atom maps in figure 4 . The precipitates were identified as $a_{2}$ based on their composition (Table 1) and based on the fact that the time and temperature of the ageing treatments lies within the $a_{2}$ phase field of the TTT curve in figure 7 . The lack of statistically relevant hardness increase upon ageing suggests that $a_{2}$ precipitation is not making a significant hardness contribution, in agreement with work by Liu et al. [5] 


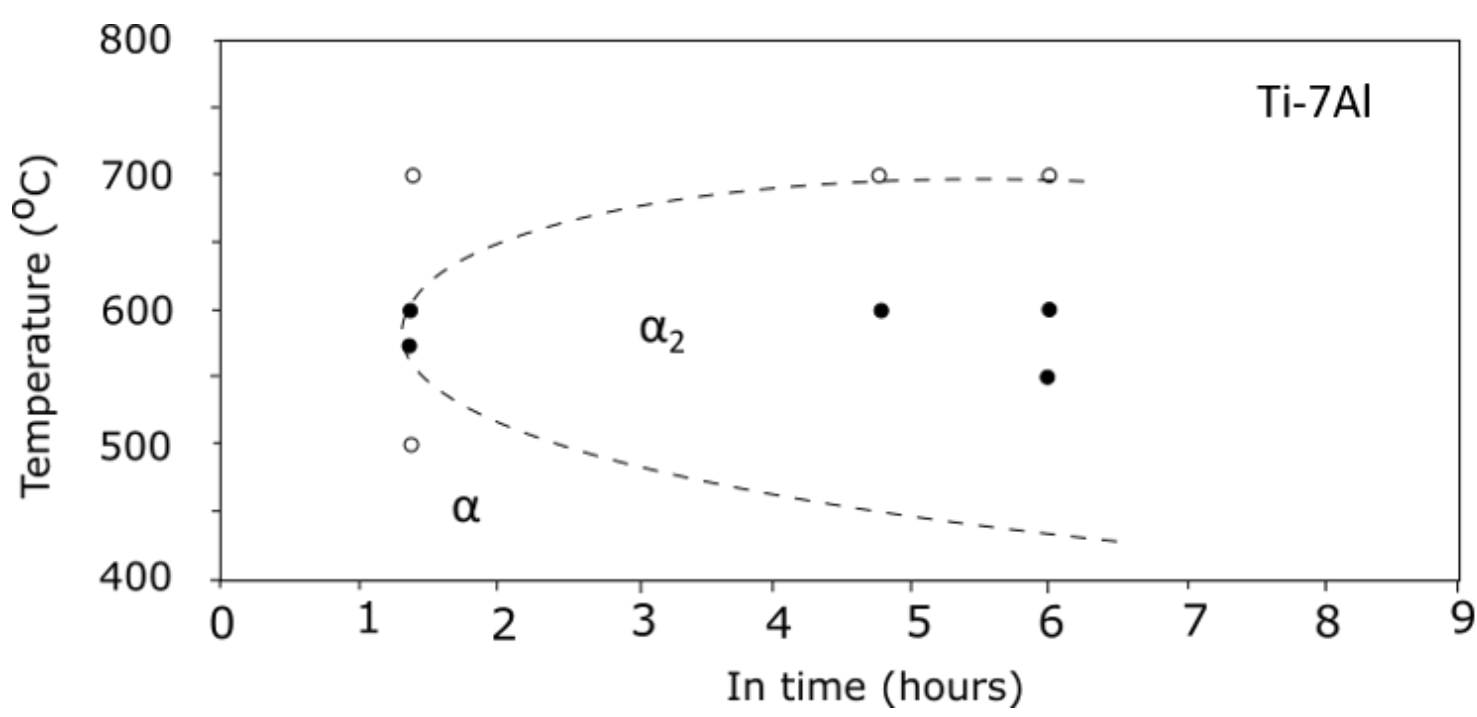

Figure 7: Time-temperature-transformation curve for Ti-7Al, redrawn from [6].

In both the 10 day aged and 49 day aged sample, the precipitates are substoichiometric. This could be because the ordered phase is defective, with titanium atoms on some aluminium sites, as described by Liew et al. [14] in their proposed conditional spinoidal mechanism for $a_{2}$ formation.

It has previously been suggested in the literature that oxygen partitions to the $a_{2}$ phase. Gehlen et al. [15] report that the octahedral interstitial site where oxygen resides is larger in the $\mathrm{Ti}_{3} \mathrm{Al}$ lattice than the regular $\mathrm{HCP}$ lattice. Ardakani et al. [6] propose that this causes oxygen to partition to, and stabilise, the $\mathrm{a}_{2}$ phase. In their work on aged Ti-8Al, Lim et al [9] also assume that oxygen must partition to and stabilise the $a_{2}$ phase based on hardness measurements. However, the current work has directly measured the oxygen concentration in both the $a_{2}$ precipitates and the matrix, and found the oxygen preferentially partitions to the matrix, as can be seen in figure 6. This agrees with the higher maximum solubility of oxygen in $a$ [16] than in $a_{2}$ [17], [18], and is in line with $a_{2}$ precipitate compositions independently measured using APT by Bagot et al. [19] in Ti-6Al-4V.

The oxygen partition coefficient calculated from the APT-measured $a$ and $a_{2}$ compositions reported by Bagot et al [19] is 1.41. The study by Bagot et al [19] was performed on Ti-64 aged for 24 hours at $800^{\circ} \mathrm{C}$, such that the $a$ and $a_{2}$ phases were approaching their corresponding theoretical oxygen solubility limits ( 34 at. $\%$ [16] in $a$ and 10-14 at. \% in $a_{2}$ [17], [18]). Consequently, this oxygen partition coefficient value can be considered as an upper limit. Thus, the lower oxygen partition coefficients measured in this current study (table 2 ) suggest that the precipitates have not yet reached equilibrium. The quantified increase in $a_{2}$ volume fraction from 0.087 to 0.13 with ageing time supports this, and suggests that the compositions and volume fraction of both phases, sensitively depend on not only exposure conditions but also long-term ageing treatments. This has clear implications for understanding vital changes in mechanical properties in any in-service components.

\section{Conclusions}

Precipitates formed during ageing of Ti-7Al containing 500 wppm 0 have been analysed using atom probe tomography (APT) and identified as the ordered $a_{2}$ phase, $\mathrm{Ti}_{3} \mathrm{Al}$. The following conclusions can be drawn:

- Oxygen partitions preferentially to the matrix rather than the $a_{2}$ precipitates. This is in agreement with previous APT studies [19] and with the theoretical solubility limits of oxygen in $a$ and $a_{2}[16]-[18]$.

- There is no statistically significant increase in hardness between the quenched and aged Ti-7Al +500 wppm $\mathrm{O}$ sample, suggesting $\mathrm{a}_{2}$ precipitation is not providing a signinficant contribution to hardening.

- $a_{2}$ formation is dependent on both exposure conditions and long term ageing treatments, as demonstrated by the increase in $a_{2}$ volume fraction from 0.087 to 0.13 from the 10 day aged to 49 day aged sample.

This study lays the foundation for future work currently being undertaken to better understand the role of oxygen in $a_{2}$ formation, and to enable better prediction of embrittlement in these vitally important alloys for the aerospace industry.

\section{Acknowledgments}

The authors would like to thank Felicity Dear and Prof. David Dye of Imperial College London for providing samples. The work in this paper was supported by EPSRC and Rolls-Royce plc under an iCase agreement. The UK National Atom Probe facility in Oxford was funded by the EPSRC under project EP/M022803/1.

\section{References}

[1] T. R. Strobridge, J. C. Moulder, and A. F. Clark, Report on Titanium combustion in turbine engines. 1979.

[2] C. Leyens and M. Peters, Titanium and Titanium Alloys. 2003.

[3] Q. Yu, R. Traylor, D. Rugg, M. Asta, D. C. Chrzan, and A. M. Minor, Science (80-. )., vol. 347, no. 6222, pp. 635-640, 2015.

[4] M. Yan, M. S. Dargusch, T. Ebel, and M. Qian, Acta Mater., vol. 68, pp. 196-206, Apr. 2014.

[5] Z. Liu and G. Welsch, Metall. Trans. A, vol. 19, no. 3, pp. 527-542, 1988.

[6] Ardakani, Titan. '95 Sci. Technol., 1995. 
[7] Z. Wu, C. Qiu, V. Venkatesh, H. L. Fraser, R. E. A. Williams, G. B. Viswanathan, M. Thomas, S. Nag, R. Banerjee, and M. H. Loretto, Metall. Mater. Trans. A Phys. Metall. Mater. Sci., vol. 44, no. 4, pp. 1706-1713, 2013.

[8] A. Radecka, J. Coakley, I. P. Jones, D. Rugg, T. C. Lindley, and D. Dye, Mater. Sci. Eng. A, vol. 650, pp. 28-37, Jan. 2016.

[9] J. Y. Lim, Metall. Trans. A, vol. 7, no. 1, pp. 139-144, 1976.

[10] M. K. Miller, K. F. Russell, and G. B. Thompson, Ultramicroscopy, vol. 102, no. 4, pp. 287-98, Mar. 2005.

[11] M. P. Moody, L. T. Stephenson, A. V. Ceguerra, and S. P. Ringer, Microsc. Res. Tech., vol. 71, no. 7, pp. 542-550, 2008.

[12] B. Gault, M. P. Moody, J. M. Cairney, and S. P. Ringer, Atom Probe Microscopy. Springer, 2012.

[13] K. S. Chan, M. Koike, B. W. Johnson, and T. Okabe, vol. 39, no. January, 2008.

[14] H. Liew, G. D. W. Smith, A. Cerezo, and D. J. Larson, Mater. Sci. Eng. A, vol. 270, no. 1, pp. 9-13, Sep. 1999.

[15] Gehlen, in The Science, Technology abd Application of Titanium, R. I. Jaffee, Ed. Pergamon Press, 1970.

[16] J. L. Murray, Phase diagrams of binary titanium alloys. ASM International, 1987.

[17] K. Das, P. Choudhury, and S. Das, ChemInform, vol. 34, no. 15, 2003.

[18] C. Y. Jones, W. E. Luecke, and E. Copland, Intermetallics, vol. 14, no. 1, pp. 54-60, 2006.

[19] P. A. J. Bagot, A. Radecka, A. P. Magyar, Y. Gong, D. C. Bell, G. D. W. Smith, M. P. Moody, D. Dye, and D. Rugg, Scr. Mater., vol. $148,2018$. 